\title{
Tannin: A new insight into a key product for the bioeconomy in forest regions
}

\author{
Mario Pagliaro, ${ }^{1}$ Lorenzo Albanese, ${ }^{2}$ Antonino Scurria, ${ }^{1}$ Federica Zabini, ${ }^{2}$ Francesco Meneguzzo,${ }^{2 *}$ Rosaria \\ Ciriminna $^{1^{*}}$ \\ ${ }^{1}$ Istituto per lo Studio dei Materiali Nanostrutturati, CNR, via U. La Malfa 153, 90146 Palermo, Italy; ${ }^{2}$ Istituto per la \\ Bioeconomia, CNR, via Madonna del Piano 10, 50019 Sesto Fiorentino (FI), Italy
}

\begin{tabular}{|c|c|}
\hline & ABSTRACT \\
\hline $\begin{array}{l}\text { Keywords: } \\
\text { Tannin } \\
\text { Forest regions } \\
\text { Bioeconomy } \\
\text { Polyphenols } \\
\text { Chestnut } \\
\text { Biomaterials } \\
\text { Organic electrodes }\end{array}$ & $\begin{array}{l}\text { Produced in many world's countries at over } 1 \text { million tonne/year rate by extraction of } \\
\text { certain woods and barks with boiling water, tannin is a class of high molecular weight } \\
\text { biophenols increasingly used in a number of industries. This study offers a new } \\
\text { bioeconomy insight into an old natural product that, we argument in this study, will } \\
\text { play a crucial role in the development of the bioeconomy of forest regions. After } \\
\text { providing an updated picture of key economic and production aspects, we show how } \\
\text { flourishing research on tannin's biological activity and technological applications has } \\
\text { revealed many new properties which are likely to drive significant growth in demand } \\
\text { in the near and mid-term future. The study concludes with selected recommendations } \\
\text { for bioeconomy scholars and for policy-makers based in forest areas. }\end{array}$ \\
\hline
\end{tabular}

\section{Introduction}

Owing its name to the Latin word tannum for "oak bark", tannin is the name of a class of oligomeric polyphenolic compounds widely employed in the leather, wine, food and beverage, chemical, cosmetic, pharmaceutical and mining industries [1]. Tannin is a key raw material of the leather industry because its biophenols combine with collagen and other proteins contained in animal skin to form insoluble compounds, transforming it into chemically and biologically stable leather due to the inhibition of proteolytic enzymes.

Excellent recent books [1] and reviews [2] are devoted to tannins, including a recent account on their biological (antioxidant, anti-inflammatory, antidiabetic, cardioprotective, wound healing and antimicrobial) properties [3], and another offering an historical perspective on different types of tannins and their applications [4].

This study offers a new insight on tannin as a key product of the emerging bioeconomy in forest regions. The bioeconomy, we remind, is the economy in which materials and functional substances are obtained from biological resources, while useful energy (electricity and heat) is obtained from renewable energy sources, particularly sunlight, wind and water [5].

First, we offer an updated outlook of key economic and market aspects often absent in scholarly papers. Then, we focus on innovation in tannin applications driven by flourishing research that might soon lead to further large increase in demand and supply.
The study concludes with selected recommendations for bioeconomy scholars and policy-makers based in forest areas.

\section{Economic and production aspects}

Pizzi, a pioneer in research on tannin-based adhesives, has recently explained how three subsequent phases characterized the economy of the tannin industry [4]. The first started around 1850 in Lyon, France, with the production of iron tannate for the black coloring of silk for women's blouses, followed a decade later by the uptake of tannin in place of oak chips from the leather industry. Finally, after World War II tannins first were adopted in the production of bio-based adhesives and, more recently, in composite materials.

The same scholar in 1982 had reported how the global tannin industry shifted from hydrolyzable tannins (mixtures of simple phenols, such as pyrogallol and ellagic acid, with gallic and digallic acid glycosides) to condensed tannins (condensed flavans containing no sugar residues). The latter already constituted over $90 \%$ of the global production ( 350,000 tonnes) of commercial tannins in 1982, due also to their new use in the preparation of adhesives and resins [6].

Produced in Europe, the Americas, Africa and Asia generally by extraction of selected woods and bark (including oak, quebracho, mimosa and chestnut trees) with hot water, tannin is generally supplied to customers either as a brown powder or as a brown-black $50 \%$ concentrated aqueous solution. 
According to a reputed market intelligence company, in 2017 the global tannin market size was estimated at 1.1 million tonnes, with four main applications: leather tanning (accounting for over $62 \%$ of the total market revenue in 2016), followed by wood adhesives, wine production and anticorrosive primers [7]. The market, expanding at an estimated compound annual growth rate (CAGR) of $6.7 \%$ was estimated to reach $\$ 3.39$ billion by 2025 .

According to another reputed market analyst publishing its forecast three years later, the global tannin market was $\$ 1.64$ billion in 2017, and was predicted to almost double to $\$ 3.05$ billion by 2024 , growing at a CAGR of $7.7 \%$ [8].

Combining the global value and production output mentioned above, the average price of tannin in 2017 was $\$ 1.5 / \mathrm{kg}$. The price reported by scholars based in France (a leading tannin production country) in 2015 varied between $€ 0.7 / \mathrm{kg}$ and $€ 1.5 / \mathrm{kg}$ depending on the purity and on the botanical resource [2].

Tannin extraction plants across the world continue to use the solid-liquid extraction process employing large amounts of hot water followed by evaporation under reduced pressure, although numerous alternative processes, from microwave- to ultrasound-assisted extraction, on laboratory scale have shown to afford higher tannin yield and reduced extraction times [9].

In brief, wood trunk or bark shredded in small chips is loaded in large autoclaves. Typical botanicals sources are black mimosa bark (Acacia mearnsii), quebracho wood (Schinopsis batansae), oak bark (Quercuss spp.), sweet chestnut (Castanea sativa) and pine (Pinus radiata and Pinus nigra) woods with production plants based in multiple countries, including France, Brazil, India, Zimbabwe, Tanzania, Kenya, Argentina, Slovenia, Italy, Canada and Switzerland.

The industrial extraction process relies in the leaching of water-soluble tannin in hot water. No acid, alkali or enzyme is used in the extraction process. However, the process is highly energy-intensive due to the large specific heat capacity of water and to 2.4 water-to-solid weight ratio typically employed. Chipping, furthermore, typically consumes $15 \mathrm{kWh} / \mathrm{t}$ of electricity.

Used since the early industry's days, the tannin extraction process until the late 1990 s saw only one significant change, when the boiling pools were replaced with countercurrent extractors. Chopped wood or bark is loaded into a battery of autoclaves working in counter-current. The extraction uses hot water and lasts about about $6 \mathrm{~h}$, [10].

Generally, a 4-5 wt\% tannin solution is thereby obtained, with an extraction yield of about 60-65\% [11]. After clarification by settling, the tannin solution is concentrated in multiple evaporators by evaporation under vacuum to limit the tannin oxidation, up to the desired concentration (>50 wt \%).

For example, one company in Brazil was reported in 2017 to use water at $75-85{ }^{\circ} \mathrm{C}$ in a series of autoclaves performing a countercurrent process to extract tannin from the bark of mimosa. The extracted liquor is concentrated and air-dried to afford a finely powdered tannin extract chiefly comprised of condensed tannins (polyflavonoids, $70-80 \%)$. The residual components of the powder are hydrocolloid gums, sugars, and other small molecule substances [12].

Tradenamed "Tantec", in the late 1990s an improved extraction process requiring significantly lower energy and of higher versatility was commercialized. Extraction takes place again via leaching of wood or bark tannin in hot water. In place of evaporation, however, now the concentration process takes place via nanofiltration through polymeric membranes (Scheme 1) affording an $50 \mathrm{wt} \%$ tannin aqueous solution [13]. If needed, a dried powder is obtained via spray-drying.

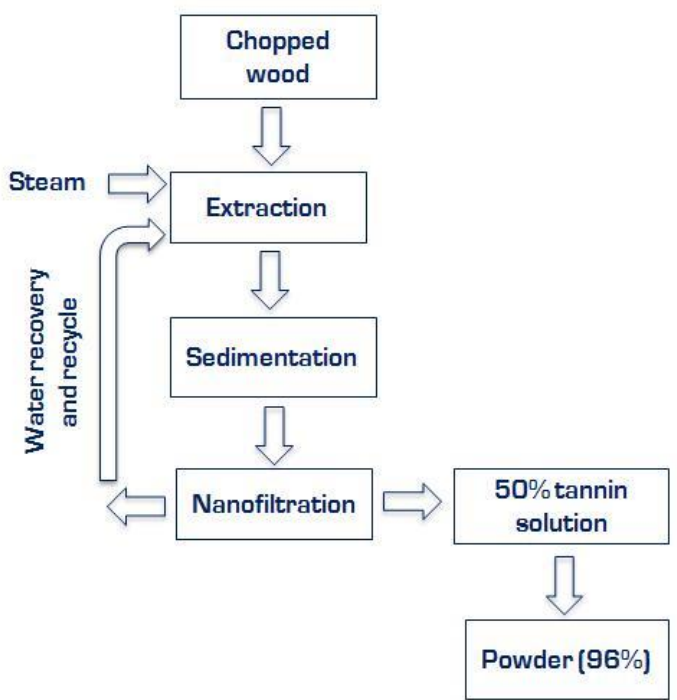

Scheme 1. The Tantec tannin extraction process (Adapted from Ref.13, with kind permission).

Contrary to the conventional process, steam or hot water is used only in the extraction step. During the crucially important concentration step, the temperature does not exceed $40^{\circ} \mathrm{C}$, with significant improvement of the occupational health and safety conditions.

The same nanofiltration can be used to recover tannin from the leather industry exhausted tanning liquors, affording a $75 \%$ reduction of chemical oxygen demand of the effluent, with direct decrease of wastewater disposal costs, saving water and energy [14].

\section{Emerging applications}

Flourishing research on tannin's biological activities and technological applications has revealed many new properties, which have expanded the demand of tannin even to the mining industry, where tannin is used to selectively separate and concentrate metal compounds in ores and other complex mixtures of materials [15]. The applications of tannin range from coagulants in potabilization of surface water and in the treatment of industrial wastewater, through dying agent for natural textile fibres [15].

To understand the environmental benefits of using biobased tannins in place of heavy metals or synthetic molecules in said applications, it is enough to consider that leather tanning using vegetable tannin replaces tanning with toxic $\mathrm{Cr}$ (III) salt, which results in occupational exposure to $\mathrm{Cr}(\amalg)$ in organic solvent or in protein bound-form (leather dust).

The latter treatment causes serious health and environmental hazard in many areas of the world hosting 
leather companies [16], whereas treatment with vegetable tannins combined with aluminum sulphate is able to afford leather nearly identical to that obtained using chromiumbased tannin [17].

The combined growth of demand of tannin from different industrial sectors has led to dramatic growth in tannin demand and supply, with global production going from $350,000 \mathrm{t}$ in 1982 to over 1.1 million $\mathrm{t}$ in 2017. Robust growth based on all existing applications of tannins has already been estimated to continue in the near term by the aforementioned market intelligence companies [7,8]. In the following we focus on two new applications of tannin that might spur large growth in demand in the near future and in the mid-term ( 5 to 10 years).

\subsection{Chestnut tannin as biopesticide and plant corroborant}

The first application has already been commercialized, following studies started in Italy in the early 2000s, and concerns the use of vegetable tannin as plant corroborant, namely as enhancer of plant defenses by improving plant resistance to harmful organisms, improving also radical development by reducing damage of the root system due to parasites [18].

Tradenamed Tannisol PB, a standard chestnut tannin powdered extract with a $75 \%$ tannin titer obtained via an extraction-nanofiltration process is commercialized as a registered plant corroborant at $>€ 9 / \mathrm{kg}$ when bought in 25 $\mathrm{kg}$ batches (otherwise $>€ 12 / \mathrm{kg}$ for a $1 \mathrm{~kg}$ batch) [19]. Approved in organic agriculture, the product is distributed by "fertigation" during the crop development cycle in the last phase of the irrigation cycle (to avoid leaks due to leaching) on fruit and vegetable crops.

The product, however, is also a biopesticide (though not registered as such) because it exerts a broad scope antimicrobial and antifungal action by inhibiting the hydrolytic enzymes (cellulases, pectinases, xylanases) used by many pathogens to penetrate plant tissues. This effect adds to its repellent action against predator insects and parasites, due to altered plant tissue flavor (astringency) and hardness.

These properties were investigated in plant in a EUfunded project between 2014 and 2016 showing evidence that the chestnut tannin extract promotes both a more vigorous plant growth, while acting as pesticide against phytopathogenic bacteria on crops such as kiwi and nematodes typical of tomato and tobacco plants [20]. Remarkably, ecotoxicity assays showed that all polyphenol extracts studied, including tannin from sweet chestnut, were free of toxic effects even at the concentration of $1 \mathrm{~g} / \mathrm{L}$, thus enhancing the agronomic and environmental relevance of this new biopesticide and plant corroborant [21].

\subsection{Tannic acid for Li-ion battery cathodes}

The second application concerns the use of tannic acid, a a low molecular weight polymer of gallic acid and 3galloylgallic acid esterified with glucose obtained by extraction with water or polar organic solvents from a number of trees including Castanea sativa (sweet chestnut) and Quercus infectoria (Aleppo oak), for producing the most important component of Li-ion batteries, namely the cathode.
In early 2021, scholars in Germany reported that it is enough to ball mill tannic acid and porous carbon easily derived from sucrose to form a stable composite (C/TAN) showing excellent capacity of $108 \mathrm{mAh} \mathrm{g}^{-1}$ at $0.1 \mathrm{~A} \mathrm{~g}^{-1}$ and low capacity fading [22]. Tannic acid, via the quinone-catecholate redox mechanism, and porous carbon, through its high surface area and excellent conductivity, are responsible for the high capacity observed.

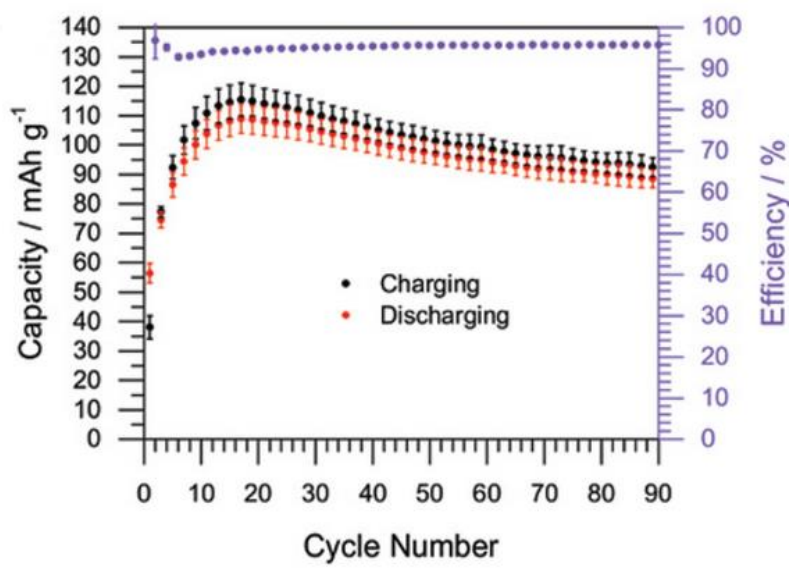

Figure 1. Electrochemical performance of C/TAN: a) chargingdischarging test at $0.1 \mathrm{~A} \mathrm{~g} \mathrm{~g}^{-1}$. (Reproduced from Ref.22, with kind permission).

In detail, the capacity using charging-discharging tests during long term cycling at $0.1 \mathrm{~A} \mathrm{~g}^{-1}$ raises during the first 17 cycles and slowly decreases afterward (Figure 1), with a capacity retention of $81.1 \%$ after 90 cycles. With approximately $3.4 \mathrm{~V}$ versus $\mathrm{Li}^{+} / \mathrm{Li}$, the cells also feature one of the highest reversible redox potentials reported for biomolecular cathodes.

(a)

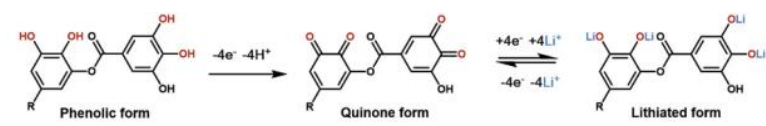

(b)

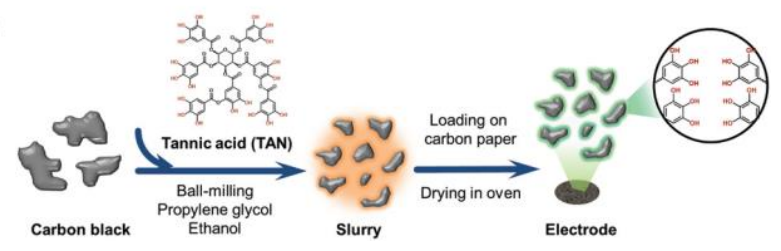

Figure 2. a) Tannic acid has a high density of redox-active o-hydroquinones. b) ball milling mechanism affording the C/TAN composite (Reproduced from Ref.22, with kind permission).

Ball milling ensures good contact between tannic acid and microporous carbon, facilitating the formation of $\pi-\pi$ stacking between the microporous carbon and tannic acid preventing dissolution of the otherwise highly soluble tannic acid (Figure 2b,), whereas the porous structure of the cathode benefits the intimate contact between the heterogenized redox-active tannic acid and the liquid electrolyte $(1.0 \mathrm{~m} \mathrm{LiPF} 6$ dissolved in 50:50 ethylene carbonate/diethyl carbonate), leading to fast reaction kinetics.

In other words, tannic used in a composite with porous bioderived carbon to form the cathode of a Li-ion battery 
achieves a high voltage, solving at the same time the main drawbacks of organic electrode materials based on the carbonyl $(\mathrm{C}=\mathrm{O})$ reaction based on the reversible electrochemical reaction between lithium ions and carbonyl groups in a conjugated organic framework (Figure 2a), namely the low potential as cathodes, the low electronic conductivity, and the high solubility of the redox-active organic material in the electrolyte [23].

Composed of lithium ion "intercalating" crystalline inorganic oxides, such as lithium ferrophosphate or lithium nickel manganese cobalt oxide, the cathode is the most expensive and important component of the Li-ion battery (LiB) [24].

Replacing the aforementioned inorganic oxides used to manufacture today's LiB cathodes with a readily available organic material such as the aforementioned tannic acid/carbon composite would not only dramatically lower LiB production costs (an ongoing trend due to massive deployment of LiB production factories in China [24]), but would also lower the market ingress costs because the material is readily prepared by simple milling of two powders [22].

\section{Outlook and perspectives}

Two main lessons of relevance for bioeconomy scholars and for policy-makers based in forestal areas originate from the present insight into the bioeconomy of tannin, an old forestal product manufactured on industrial scale since more than two centuries.

First, tannin has an exceptionally versatile chemistry and biochemistry which will drive applications in numerous other fields, well beyond today's four dominant uses (leather tanning, wood adhesives, wine production and anticorrosive primers).

Likewise to the owners of tannin production plants, most scholars engaged in tannin research in the early 1980s would have met with the skepticism the forecast that the tannin market was going to more than triple from 350,000 tonnes in 1982 to 1.1 million tonnes in 2017.

The same will now occur with completely new applications of tannin and its main components. One, we forecast, is as biopesticide and plant corroborant, a field pioneered in Italy [18]. Another will be in Li-ion batteries, as recently demonstrated on laboratory scale in Germany [22].

Second, new green chemistry production and purification technologies [9] will be used to produce the high quality tannin extracts for advanced usages in a fourth wave of innovation anticipated herein pursuing to Pizzi's three waves of tannin production (iron tannate for black coloring of silk, tannin in place of oak chips from the leather industry, and tannin in bio-based adhesives) [4].

Likewise to what happened with the rediscovery of the precious role of phlorotannins in protecting marine oils from oxidation and autooxidation (and the dangers associated with their removal during the production of refined fish oil to manufacture nutraceutical supplements) [25], also in the case of tannin, students find a clear example of how progress in science and technology is far from being linear [26].
Tannin, a forestal bioproduct, in 2017 was already sold at $\$ 1.5 / \mathrm{kg}$ even though production (and thus supply) had expanded more than three times in three decades. In advanced applications such as the aforementioned use as environmentally friendly agrochemical, powdered tannin is sold at prices approaching $\$ 10 / \mathrm{kg}$ on scale, and well beyond $\$ 12 / \mathrm{kg}$ for small scale usage such as in protecting garden plants.

If and when production of Li-ion battery cathodes based on tannic acid will commence, which requires to demonstrate prolonged stability in storing and delivering electricity at the original high voltage (a typical LiB using a $\mathrm{LiFePO}_{4}$ cathode lasts ten years or more if charged and managed correctly), supply of high purity tannic acid currently sold by chemical suppliers at $\$ 200-300 / \mathrm{kg}$ [27] will be required.

Aware of the new as well as of the emerging uses of tannin in advanced technologies in numerous industries, today's tannin manufacturers currently mostly using the old production route based on extraction with boiling water using counter-current extractors will progressively adopt new extraction and concentration technologies, so far chiefly confined to laboratory scale [9].

Eventually, local communities and indigenous peoples of forest zones will benefit from both increasing revenues derived from increased production of tannin, as well as from reduced environmental impact of tomorrow's tannin production plants which will rely on the aforementioned green extraction and green purification technologies [9].

Likewise to what happens with overfishing and the need to increase the revenues of fisheries for example through valorization of fish leftovers by extracting omega-3 lipids with new green extraction technology [28], the latter is a crucial factor to arrest and prevent deforestation. New revenues and new jobs related to tannin's production would provide new financial resources supplementing the income of residents in forest areas, thereby establishing a realistic alternative to cut more trees for generating new revenues.

This is especially relevant considering that tannin can be successfully extracted from bark residue of the timber industry, such as in the case of the bark of Pinus pinaster (maritime pine) rich in procyanidin condensed tannins [29].

Rather than relying on false promises made in the interest of profits of powerful transnational companies as found in an interesting analysis of alleged "value-free" discourse of EU and US governments on the bioeconomy [30], the social and economic benefits of the bioeconomy of tannin are already evident, with a diffuse global tannin industry and market due to the presence of numerous regional and domestic players in different countries [31].

Beyond numerous new jobs for plant workers, significant professional opportunities will originate from the evolving tannin industry: in research (for life scientists, chemists, and agronomists), in designing and running the new tannin production plants (for engineers and technologists), as well as in managing the existing and the new tannin production companies (for managers and for marketing managers).

This study will hopefully contribute to accelerate the forecasted progresses. 


\section{Author ORCID Information}

Mario Pagliaro: 0000-0002-5096-329X

Lorenzo Albanese: 0000-0002-4549-8514

Antonino Scurria: 0000-0001-5624-6833

Federica Zabini: 0000-0003-1505-0839

Francesco Meneguzzo: 0000-0002-5952-9166

Rosaria Ciriminna: 0000-0001-6596-1572

\section{Corresponding Authors}

E-mail: rosaria.ciriminna@cnr.it

E-mail: francesco.meneguzzo@cnr.it

Notes: The author declares no competing interest. The author received no external funding for this research.

\section{Acknowledgements}

This study is dedicated to Professor Antonio Pizzi, University of Lorraine, for all he has done to advance the first high-value chemical applications of tannin.

\section{References}

1. A. Aires (Ed.), Tannins: Structural Properties, Biological Properties and Current Knowledge, IntechOpen, London: 2020. http://dx.doi.org/10.5772/intechopen. 80170

2. A. Arbenz, L. Avérous, Chemical modification of tannins to elaborate aromatic biobased macromolecular architectures, Green Chem. 2015, 17, 2626-2646. https://doi.org/10.1039/c5gc00282f

3. Fraga-Corral, M.; Otero, P.; Echave, J.; GarciaOliveira, P.; Carpena, M.; Jarboui, A.; Nuñez-Estevez, B.; Simal-Gandara, J.; Prieto, M.A. By-Products of Agri-Food Industry as Tannin-Rich Sources: A Review of Tannins' Biological Activities and Their Potential for Valorization. Foods 2021, $10, \quad 137$. https://doi.org/10.3390/foods10010137

4. A. Pizzi, Tannins: Prospectives and Actual Industrial Applications, Biomolecules 2019, 9, 344. https://doi.org/10.3390/biom9080344

5. M. Pagliaro, The Central Role of chemistry in the Transition to the Solar Economy: The Outcomes of two Lectures at the Russian Academy of Sciences, Gen. Chem. 2020, 6, 200007. https://doi.org/10.21127/yaoyigc20

6. A. Pizzi, Condensed Tannins for Adhesives Ind. Eng. Chem. Prod. Res. Dev. 1982, 21, 359-369. https://doi.org/10.1021/i300007a005

7. Grand View Research, Tannin Market Size, Share \& Trends Analysis Report By Sources (Plants, Brown Algae), By Product (Hydrolysable, Non-hydrolysable, Phlorotannins), By Application (Leather Tanning, Wine Production, Wood Adhesives), \& Segment Forecasts, 20142025, San 2017. https://www.grandviewresearch.com/industryanalysis/tannin-market

8. Energias Market Research, Global Tannin Market Outlook, Trend and Opportunity Analysis, Competitive
Insights, Actionable Segmentation \& Forecast 2024, Uttarakhand: 2018.

9. P. de Hoyos-Martinez, J. Merle, J. Labidi, F. CharrierEl Bouhtoury, Tannins extraction: A key point for their valorization and cleaner production, J. Clean. Prod. 2019, 206,

$1138-1155$.

https://doi.org//10.1016/j.jclepro.2018.09.243

10. G. Matturro, P. Danesi, A. Festuccia, C. Mustacchi, Process and plant to extract and concentrate tannins from wood and from other natural products, US7145031B1, 1997.

11. R. Jullien, D. Ayme, Le tannnage vegetal, Centre Technique du Cuir, Lyon: 1998.

12. A. L. Missio, B. Tischer, P. S. B. dos Santos, C. Codevilla, C. R. de Menezes, J. S. Barin, C. R. Haselein, J. Labidi, D. A. Gatto, A. Petutschnigg, G. Tondi, Statcounter, Analytical characterization of purified mimosa (Acacia mearnsii) industrial tannin extract: Single and sequential fractionation, Sep. Purif. Technol. 2017, 186, 218-225. https://doi.org/10.1016/j.seppur.2017.06.010

13. Proras, Teconologia e Impianti per Produzione Estratti Tannici,

2000.

http://web.tiscali.it/proras/tantectipimpita.htm (last time accessed February 3, 2021).

14. A. Cassano, J. Adzet, R. Molinari, M. G Buonomenna, J. Roig, E. Drioli, Membrane treatment by nanofiltration of exhausted vegetable tannin liquors from the leather industry, Water Res. 2003, 37, 2426-2434. https://doi.org/10.1016/S0043-1354(03)00016-2

15. Fraga-Corral, M.; García-Oliveira, P.; Pereira, A.G.; Lourenço-Lopes, C.; Jimenez-Lopez, C.; Prieto, M.A.; Simal-Gandara, J. Technological Application of TanninBased Extracts, Molecules 2020, 25, 614. https://doi.org/10.3390/molecules25030614

16. J. Al-Mizan, M.A.I. Juel, M.S. Alam, J. Pichtel, T. Ahmed, Environmental and health risks of metalcontaminated soil in the former tannery area of Hazaribagh, Dhaka, SN Appl. Sci. 2020, 2, 1915. https://doi.org/10.1007/s42452-020-03680-4

17. C. R. China, M. M. Maguta, S. S. Nyandoro, A. Hilonga, S. V. Kanth, K. N. Njau, Alternative tanning technologies and their suitability in curbing environmental pollution from the leather industry: A comprehensive review, Chemosphere 2020, 254, 126804. https://doi.org/10.1016/j.chemosphere.2020.126804

18. S. Miele, S. Tegli, C. Garcia Izquierdo, M. Cerboneschi, E. Bargiacchi, Hydrolysable Tannins in Agriculture, Tannins Structural Properties, Biological Properties and Current Knowledge, A. Aires (Ed.), IntechOpen, London: 2019. DOI: https://doi.org/10.5772/intechopen.86610

19. SKL, Tannisol PB, 2021. See at the URL: https://shopping.agrimag.it/it/v2021/prodotti/corroboranti/1583 -tannisol-pb (last time accessed, February 4, 2021).

20. E. Bargiacchi, M. Campo, A. Romani, G. Milli, S. Miele, Hydrolysable tannins from sweet chestnut (Castanea sativa Mill.) to improve tobacco and food/feed quality. Note 1: Fraction characterization, and Tobacco biostimulant effect for gall-nematode resistance, AIMS Agric. Food 2017 , 2 , 324-338. 
21. EU Life Programme, Evergreen Final Report, Life Project Number LIFE13, ENV/IT/000461, 2016. http://lifeevergreen.com/2018/07/23/final-report/

22. I. K. Ilic, A. Tsouka, M., Perovic, J. Hwang, T. Heil, F. F. Loeffler, M. Oschatz, M. Antonietti, C. Liedel, Sustainable Cathodes for Lithium-Ion Energy Storage Devices Based on Tannic Acid-Toward Ecofriendly Energy Storage, Adv. Sustainable Syst. 2021, 5, 2000206. https://doi.org/10.1002/adsu.202000206

23. J. J. Shea, C. Luo, Organic Electrode Materials for Metal Ion Batteries, ACS Appl. Mater. Interfaces 2020, 12, 5361-5380. https://doi.org/10.1021/acsami.9b20384

24. M. Pagliaro, F. Meneguzzo, The driving power of the electron, J. Phys. Energy 2019, 1, 011001. https://doi.org/10.1088/2515-7655/aacd9f

25. E. O. Elvevoll, B. Østerud, Impact of processing on nutritional quality of marine food items, Forum Nutr. 2003, 56, 337-340.

26. J.-M. Lévy-Leblond, (Re)mettre la science en culture: de la crise épistémologique a l'exigence éthique. Seminar "Marcello Carapezza", Palermo, March 27, 2007. https://hal.archives-ouvertes.fr/hal-

01197326/file/C56Levy.pdf

$27 . \quad$ ChemicalBook.com,

2021.

https://www.chemicalbook.com/Price/Tannic-acid.htm

28. R. Ciriminna, A. Scurria, A. S. Fabiano-Tixier, C. Lino, G. Avellone, F. Chemat, M. Pagliaro, Omega-3 Extraction from Anchovy Fillet Leftovers with Limonene: Chemical, Economic and Technical Aspects, ACS Omega 2019, 4 , 15359-15363. https://doi.org/10.1021/acsomega.9b01168

29. H. Bacelo, B.R.C. Vieira, S.C.R. Santos, R.A.R. Boaventura, C.M.S. Botelho, Recovery and valorization of tannins from a forest waste as an adsorbent for antimony uptake, J. Clean. Prod. 2018, 198, 1324-1335. https://doi.org/10.1016/j.jclepro.2018.07.086

30. V. Sodano, Pros and cons of the bioeconomy: a critical appraisal of public claims through Critical Discourse Analysis, 2 $2^{\text {nd }}$ AIEAA Conference - Between Crisis and Development: which Role for the Bio-Economy. 6-7 June 2013. https://doi.org/10.22004/ag.econ.149895

31. Mordor Intelligence, Tannin Market - Growth, Trends, COVID-19 Impact, and Forecasts (2021-2026), Hyderabad: 2020. 